\title{
Association between biomechanical parameters and concussion in helmeted collisions in American football: a review of the literature
}

\author{
Jonathan A. Forbes, M.D., ${ }^{1}$ Ahmed J. Awad, M.D., ${ }^{2}$ Scott Zuckerman, M.D., ${ }^{1}$ \\ Kevin Carr, B.S., ${ }^{3}$ ANd Joseph S. Cheng, M.D. ${ }^{1}$ \\ ${ }^{1}$ Department of Neurological Surgery, Vanderbilt University Medical Center; ${ }^{3}$ Vanderbilt School of Medicine, \\ Vanderbilt University Medical Center, Nashville, Tennessee; and ${ }^{2}$ Faculty of Medicine and Health Sciences, \\ An-Najah National University, Nablus, West Bank, Palestine
}

Object. The authors' goal was to better define the relationship between biomechanical parameters of a helmeted collision and the likelihood of concussion.

Methods. The English-language literature was reviewed in search of scholarly articles describing the rotational and translational accelerations observed during all monitored impact conditions that resulted in concussion at all levels of American football.

Results. High school players who suffer concussion experience an average of $93.9 \mathrm{~g}$ of translational acceleration (TA) and $6505.2 \mathrm{rad} / \mathrm{s}^{2}$ of rotational acceleration (RA). College athletes experience an average of $118.4 \mathrm{~g}$ of TA and $5311.6 \mathrm{rad} / \mathrm{s}^{2}$ of RA. While approximately $3 \%$ of collisions are associated with TAs greater than the mean TA associated with concussion, only about $0.02 \%$ of collisions actually result in a concussion. Associated variables that determine whether a player who experiences a severe collision also experiences a concussion remain hypothetical at present.

Conclusions. The ability to reliably predict the incidence of concussion based purely on biomechanical data remains elusive. This study provides novel, important information that helps to quantify the relative insignificance of biomechanical parameters in prediction of concussion risk. Further research will be necessary to better define other factors that predispose to concussion.

(http://thejns.org/doi/abs/10.3171/2012.9.FOCUS12288)

\section{KEY WoRDS • concussion • translational acceleration • rotational acceleration}

$\mathrm{C}$ ONCUSSION occurs when kinetic energy from a collision is transferred to underlying neural elements, resulting in tensile strain and postinjury neural dysfunction. ${ }^{25}$ Because accurate measurement of tensile strain during helmeted impacts is not feasible, alternative parameters, such as head acceleration, have been tracked. ${ }^{4}$ Previous research has sought to better define the relationship between peak translational and rotational acceleration and concussion. ${ }^{18}$ However, various studies have published conflicting results as to what constitutes a "dangerous" level of acceleration..$^{3,12,18}$ The purpose of this literature review is to better define the relationship between TA, RA, and concussion and to identify additional variables that merit further analysis in future studies.

\footnotetext{
Abbreviations used in this paper: $\mathrm{HIT}=$ Head Impact Telemetry; NOCSAE = National Operating Committee on Standards for Athletic Equipment; RA = rotational acceleration; $\mathrm{TA}=$ translational acceleration.
}

\section{Methods}

Records from MEDLINE and PubMed were searched to identify all studies pertaining to concussion in American football. The terms "translational acceleration," "rotational acceleration," "concussion," "American football," "biomechanical parameters," and "peak impact conditions" were used as Medical Subject Heading terms and text words. The reference lists of these articles were examined to identify additional relevant research.

A focused search was then performed to assess the average translational and rotational accelerations associated with actual collisions resulting in concussive episodes. An additional search was then performed to identify studies that reported individual recordings of accelerations associated with collisions that had resulted in concussion. This was done so that a weighted mean of all individual translational and rotational accelerations associated with concussions could be calculated. A third search was conducted to 


\section{J. A. Forbes et al.}

identify studies that had reported peak accelerations (measured as top $1 \%$ and $5 \%$ of impacts) for both high school and collegiate levels to gain an idea of how collisions that resulted in concussion compared with a composite, unfiltered distribution of collisions.

\section{Results}

After an extensive review of the literature, 7 papers were identified that reported the average translational and rotational accelerations associated with actual collisions resulting in concussive episodes (Table 1). ${ }^{2,3,5,7,9,14,20,21}$ Five of these studies dealt with collegiate athletes, and 2 reported values obtained from high school players. Of the approximately 560,000 collisions that were recorded, 98 collisions $(0.02 \%)$ resulted in concussion.

Two studies identified the individual accelerations experienced by 23 concussed high school players (Table 2). These players experienced, on average, $6505.2 \mathrm{rad} / \mathrm{s}^{2}$ of RA and $93.9 g$ of TA during the collisions that resulted in concussion. This search was then repeated for college athletes, yielding 3 studies that reported the accelerations experienced by 21 concussed players (Table 3 ). These players experienced, on average, $5311.6 \mathrm{rad} / \mathrm{s}^{2}$ of RA and $118.4 \mathrm{~g}$ of TA during the collisions that resulted in concussion.

Two studies were identified that reported peak accelerations obtained from the top $1 \%$ of measured impacts, at the high school and collegiate levels (Table 4). In the report by Schnebel et al., ${ }^{21}$ the top $1 \%$ of college impacts was associated with a TA of $127.8 \mathrm{~g}$. In contrast, the top $1 \%$ of impacts at the high school level was associated with a TA of $114.5 \mathrm{~g}$.

In all of the aforementioned studies, players wore helmets equipped with the HIT system (Simbex) to measure accelerations using a wireless device that provided real-time data from helmeted collisions. ${ }^{2,3,5,7,9,14,20,21}$ The HIT system consists of a player unit, signal receiver, and laptop computer system located on the sidelines. Translational (linear) acceleration was measured directly, while peak RA was estimated from a TA vector and an assumed point of rotation. The accuracy of the HIT system has been validated in previous studies. ${ }^{7}$ In addition to the description above, the study by Rowson et al. ${ }^{20}$ provided an estimate of RA tolerance derived from direct accelera- tion measurements from an instrumented human volunteer using a 6-df device.

Concussion definitions were consistent throughout the studies. Broglio et al. ${ }^{2,3}$ and Rowson et al. ${ }^{20}$ used the following definition of concussion provided by the American Academy of Neurology: "A trauma-induced alteration in mental status that may or may not involve loss of consciousness." Guskiewicz and colleagues ${ }^{14}$ defined concussion as an injury resulting from a blow to the head that caused an alternation in mental status and one or more of the following symptoms: headache, nausea, vomiting, dizziness/balance problems, fatigue, trouble sleeping, drowsiness, sensitivity to light or noise, blurred vision, difficulty remembering, and difficulty concentrating. Schnebel et al. ${ }^{21}$ defined concussion as a traumatically induced neurological dysfunction, manifested primarily by transient alternations in consciousness and cognition.

Concussions in all studies were diagnosed based on a combination of detailed history, clinical evaluation, and review of game film., ${ }^{5,21}$ Additionally, a comparison was made between player's baseline cognitive status (as assessed by various programs, including HeadMinder and ImPACT) and the individual's postinjury evaluation. ${ }^{2,5,7}$ When an injury appeared serious or symptoms remained persistent, additional neuropsychological and neuroimaging tests were performed on a selective basis. While some studies (for example, that by Guskiewicz et al. ${ }^{14}$ ) used symptom grading in their assessment, this was not true for all studies (Broglio et al. ${ }^{2}$ did not grade injuries because of the general lack of support and evidence for the use of grading scales).

\section{Discussion}

The quest to better understand the relationship between the biomechanical parameters of a collision and the physiognomic repercussions has been ongoing for more than half a century. In an early landmark study, Lissner et al. ${ }^{16}$ performed drop tests on cadaveric specimens at Wayne State University and detailed the relationship between TA, impulse duration, and skull fracture (of particular note, concussions during this era were often defined as "posttraumatic episodes of unconsciousness" and researchers using cadaveric specimens often hypoth-

TABLE 1: Studies reporting the average translational and rotational accelerations associated with concussive episodes*

\begin{tabular}{lccccc}
\hline \multicolumn{1}{c}{ Authors \& Year } & High School vs College & No. of Impacts & No. of Concussions & Mean TA $(g)$ & Mean RA $\left(\mathrm{rad} / \mathrm{s}^{2}\right)$ \\
\hline Duma et al., 2005 & college & 3,312 & 1 & 81 & 5,590 \\
Guskiewicz et al., 2007 & college & 104,714 & 13 & 102.8 & $5,311.6$ \\
Brolinson et al., 2006 & college & 11,604 & 3 & 103.3 & $\mathrm{NR}$ \\
Funk et al., 2012 & college & 37,128 & 4 & 145 & $\mathrm{NR}$ \\
Rowson et al., 2012 & college & 301,034 & 57 & $\mathrm{NR}$ & 5,022 \\
Broglio et al., 2010 & high school & 54,247 & 13 & 96.1 & $5,582.3$ \\
Broglio et al., 2011 & high school & 101,994 & 20 & 93.6 & $6,402.6$ \\
total & & 559,786 & $98(0.02 \%)$ & & \\
\hline
\end{tabular}

* NR = not reported. 
Association between acceleration and concussion

TABLE 2: Recordings of accelerations associated with individual collisions resulting in concussion in high school players

\begin{tabular}{|c|c|c|c|c|}
\hline Authors \& Year & Designation & RA of Collision (rad/s²) & TA of Collision $(\mathrm{g})$ & Days of Recovery \\
\hline \multirow[t]{20}{*}{ Broglio et al., 2011} & Player 1 & $5,582.6$ & 102.6 & 1 \\
\hline & Player 2 & $5,929.4$ & 146 & 10 \\
\hline & Player 3 & $5,581.9$ & 74.6 & NR \\
\hline & Player 4 & $7,103.1$ & 122 & 8 \\
\hline & Player 5 & $7,992.9$ & 130.6 & NR \\
\hline & Player 6 & $9,515.5$ & 111.3 & 4 \\
\hline & Player 7 & $6,634.3$ & 107.6 & 8 \\
\hline & Player 8 & $6,640.7$ & 116.2 & 3 \\
\hline & Player 9 & $8,529.7$ & 97.6 & 1 \\
\hline & Player 10 & 5,933 & 66.3 & NR \\
\hline & Player 11 & $3,317.5$ & 114.4 & NR \\
\hline & Player 12 & $6,516.2$ & 74 & 2 \\
\hline & Player 13 & $7,997.2$ & 99.1 & 1 \\
\hline & Player 14 & $7,967.1$ & 100.9 & 4 \\
\hline & Player 15 & $4,870.2$ & 85.3 & NR \\
\hline & Player 16 & $4,664.6$ & 52.7 & NR \\
\hline & Player 17 & $4,280.4$ & 48 & NR \\
\hline & Player 18 & $4,655.3$ & 66.5 & NR \\
\hline & Player 19 & $4,858.1$ & 52.9 & NR \\
\hline & Player 20 & $9,481.5$ & 102.7 & NR \\
\hline \multirow[t]{3}{*}{ Broglio et al., 2010* } & Player 21 & $6,009.4$ & 110 & 1 \\
\hline & Player 22 & $7,384.8$ & 81.5 & 3 \\
\hline & Player 23 & $8,173.1$ & 96.1 & 1 \\
\hline mean & & $6,505.2$ & 93.9 & \\
\hline
\end{tabular}

* Ten of the 13 concussion data points initially published in the Broglio et al. 2010 study were republished in the Broglio et al. 2011 study (these 10 data points are listed under Broglio et al. 2011 in the table). Thus, only the 3 data points that were not republished are illustrated under Broglio et al. 2010 in this table.

esized that the energy required for skull fracture would be roughly equivalent to the amount of energy necessary to result in concussive injury). Additional studies, also performed at Wayne State University, sought to better elucidate the relationship between TA, impulse duration, and degree of concussion in a canine model. ${ }^{13}$ In 1966, Gadd ${ }^{11}$ used this data curve to describe a new entity know as the severity index to predict the threshold of life-threatening injury. The formula used to calculate the severity index exponentially weighted TA to a power of 2.5 prior to integration with respect to time. ${ }^{10}$ In 1973 , the NOCSAE incorporated this measure in its recommendations for sports helmets. The pass-fail value for severity index was changed to its current value of 1200, in line with changes in federal motor vehicle safety standards in 1996.

The search for a "threshold" acceleration, below which concussive injury is prevented, has continued into the 21st century. ${ }^{18,22}$ In 2003, Pellman and colleagues ${ }^{18}$ purported that a peak translational acceleration of $98.9 \mathrm{~g}$ was associated with a $74 \%$ risk of cerebral injury, arguing that helmet constructs should be measured by their ability to limit TA. Subsequent reports have suggested that the frequency of injuries reported by Pellman et al. are grossly overestimated, attributing inaccuracies to selection bias associated with inclusion and measurement of only those impacts associated with concussion. ${ }^{3}$ In recent years, many reports have offered insight regarding the predictive value of additional surrogate parameters in helmeted impacts. A comprehensive study by Greenwald et al. ${ }^{12}$ reported that a combination of variables, including TA, RA, impact location, and head injury criterion, provided the highest sensitivity with regard to prediction of concussion.

Despite a considerable amount of speculation, the literature search performed in this review highlights the indistinct and complex relationship between acceleration and concussive symptoms. Tables 2 and 3 list the average TAs experienced by high school and collegiate players who experienced a concussion $(93.9 g$ and $118.4 g$, respectively). A review of Table 4 helps to gauge the relative severity of these statistics. The aforementioned TAs are lower than the mean numbers reported for the top $1 \%$ of collisions for each respective level, but greater than the mean numbers reported for the top $5 \%$ of collisions, placing the mean TA associated with collision somewhere between the 95th and 99th percentiles. This estimation is consonant with the report by Schnebel et al., ${ }^{21}$ who estimated that most concussions were associated with accelerations involving the top $3 \%$ of impacts. However, while 


\section{J. A. Forbes et al.}

TABLE 3: Recordings of accelerations associated with individual collisions resulting in concussion in collegiate players

\begin{tabular}{|c|c|c|c|c|}
\hline Authors \& Year & Designation & RA of Collision (rad/s²) & TA of Collision $(g)$ & Days of Recovery \\
\hline \multirow[t]{4}{*}{ Funk et al., 2007} & Player 1 & NR & 81 & NR \\
\hline & Player 2 & NR & 139 & NR \\
\hline & Player 3 & NR & 172 & $N R$ \\
\hline & Player 4 & NR & 200 & $N R$ \\
\hline \multirow[t]{13}{*}{ Guskiewicz et al., 2007} & Player 5 & 163.35 & 60.51 & NR \\
\hline & Player 6 & $5,923.27$ & 63.84 & NR \\
\hline & Player 7 & $3,637.48$ & 77.68 & NR \\
\hline & Player 8 & $5,299.57$ & 84.07 & NR \\
\hline & Player 9 & $3,274.05$ & 85.1 & $N R$ \\
\hline & Player 10 & $8,994.40$ & 99.74 & NR \\
\hline & Player 11 & $1,085.26$ & 100.36 & NR \\
\hline & Player 12 & $6,837.62$ & 102.39 & 11 \\
\hline & Player 13 & $2,811.45$ & 107.07 & NR \\
\hline & Player 14 & $6,632.77$ & 109.23 & NR \\
\hline & Player 15 & $7,974.22$ & 119.88 & NR \\
\hline & Player 16 & $1,020.0$ & 157.5 & NR \\
\hline & Player 17 & $15,397.07$ & 168.71 & NR \\
\hline \multirow[t]{3}{*}{ Funk et al., $2012^{*}$} & Player 18 & NR & 98 & NR \\
\hline & Player 19 & NR & 164 & NR \\
\hline & Player 20 & NR & 178 & NR \\
\hline mean & & $5,311.6$ & 118.4 & \\
\hline
\end{tabular}

* One of the 4 concussion data points initially published in the Funk et al. 2007 study was republished in the Funk et al. 2012 study.

Thus, only the 3 data points that were not republished are listed under Funk et al. 2012 in this table.

these accelerations are encountered on a relatively frequent basis in American football (by definition, approximately 1 in 33 collisions), concussions are, in fact, decidedly rare events. Table 1 illustrates that across 7 studies and nearly 560,000 collisions, only 98 concussions (approximately 1 concussion per every 5000 collisions) were reported. Otherwise stated, while approximately 3\% of collisions are associated with TAs greater than the mean TA associated with concussion, only about $0.02 \%$ of collisions actually result in a concussion.

It is intuitive to surmise that the more violent a collision, the more likely the players involved will suffer concussions. This notion is supported by decades of animal, human, and cadaveric research, which has noted an increased incidence of intracranial injury with increasing head accelerations..$^{11,13,16}$ Thus, it is not surprising that the vast majority of interventions meant to decrease head in- jury have addressed biomechanical factors. In the 1970s, in particular, many changes were made in attempt to decrease the collision-related head accelerations. Widespread adoption of the NOCSAE criteria for helmet safety in 1974 resulted in an approximately $50 \%$ decline in the severity index relative to helmets' prior certification score. ${ }^{15,17}$ This was followed by a 1976 rule that prohibited initial contact of the opponent's helmet when tackling or blocking. ${ }^{6} \mathrm{Im}-$ provements in helmet technology have paralleled changes in regulation. One notable example is the switch from suspension helmets to padded helmets, which have been shown to increase the time of force application and decrease peak acceleration. ${ }^{1}$ Incremental biomechanical advances in newer padded helmets have been documented in other studies. ${ }^{24}$ However, despite numerous improvements in both the rules of the game and helmet design and technology, concussions continue to be a common problem.

TABLE 4: Peak accelerations from the top $1 \%$ of measured impacts, as measured by various studies, for high school and collegiate levels

\begin{tabular}{cclcccc}
\hline & & College vs & Mean TA $(g)$, & Mean TA $(g)$, & Mean RA (rad/s $\left.\mathrm{s}^{2}\right)$, \\
Authors \& Year & No. of Impacts & High School & Game vs Practice & Top 1\% & Top 5\% & Top 1\% \\
\hline Schnebel et al., 2007 & 54,154 & college & game + practice & 127.8 & 84 & NR \\
Greenwald et al., 2008 & 8,326 & high school & game + practice & 114.5 & 77.9 & NR \\
& 289,916 & $\begin{array}{c}\text { high school + } \\
\text { college }\end{array}$ & game & 103.4 & NR & $6,990.5$ \\
\hline
\end{tabular}


Based on information collected in this study, approximately 2 in 10,000 collisions result in a concussion. This figure is consistent with previous studies that have estimated approximately 3 concussions per 10,000 collisions. ${ }^{19}$ As mentioned above, it is relatively frequent for impact accelerations to surpass the average mean acceleration associated with concussions; however, less than $1 \%$ of collisions that surpass the average mean acceleration associated with concussion actually result in concussion. In light of the wide variations noted above between the magnitude of acceleration in a collision and the appearance of postconcussive sequelae, additional research has focused on the identification of other influential variables. One such putative variable involves the contribution of cumulative subconcussive impacts. While older studies suggested that cumulative subconcussive impacts might potentially play a role in predisposing players to concussive symptoms, a more recent study by Broglio et al. ${ }^{2}$ failed to find an association between cumulative impact profiles and concussive symptoms. ${ }^{5}$ However, it remains possible that genetic and age-related factors may influence the biological recovery of neurons following subclinical injury and that the influence of cumulative subconcussive impacts may vary across subgroups. In addition to the potential contribution of cumulative subconcussive impacts, a recent study by Zhang et al. ${ }^{25}$ applied National Football League (NFL) concussion data to a finite element mod$\mathrm{el}$ and found that the amount of shear stress placed on brainstem structures might be an important and largely unheralded risk factor for development of concussion. A study by Viano et al. ${ }^{23}$ demonstrated various areas of strain concentration or "hot spots" following reenactment of NFL collisions that eventuated in concussion. Both of these studies highlight the very important consideration that a number of biomechanical and anatomical variables specific to a collision influence the relatively small region of the brain that is subject to the greatest amount of deformation. Moreover, which regions of the brain were subjected to increased strain in previous collisions, the magnitude of these strain(s), and genetic and temporal aspects of recovery result in additional degrees of variability. In light of the intricate nature of these contributing factors, it is not surprising that traditional methods seeking to define a simple, biomechanical threshold of concussive injury have fallen short.

Hope remains that future scientific developments will further elucidate the full set of variables that determine the cumulative threshold of tissue strain and acute and chronic neurological dysfunction. One potential next step for advancement would involve the marriage of current systems used to track in vivo biomechanical parameters with finite element technology used to predict patterns of tissue strain in response to various biomechanical variables. While both the great number of variables involved and the inherent limitations of study of human subjects makes systematic analysis of this topic difficult, further analysis is warranted.

\section{Conclusions}

While approximately $3 \%$ of collisions are associated with TAs greater than the mean TA associated with con- cussion, only about $0.02 \%$ of collisions actually result in a concussion. Despite the exhaustive collection of biomechanical data that has occurred over the past 15 years, the ability to reliably predict the incidence of concussion based purely on biomechanical data remains elusive. Further research of other influential variables will be necessary to fully elucidate this disparity.

\section{Disclosure}

The authors report no conflict of interest concerning the materials or methods used in this study or the findings specified in this paper.

Author contributions to the study and manuscript preparation include the following. Conception and design: Forbes. Acquisition of data: Forbes, Awad. Analysis and interpretation of data: Forbes, Awad. Drafting the article: Forbes, Cheng. Critically revising the article: Forbes, Zuckerman, Carr. Reviewed submitted version of manuscript: Forbes. Approved the final version of the manuscript on behalf of all authors: Forbes.

\section{References}

1. Bishop PJ, Norman RW, Kozey JW: An evaluation of football helmets under impact conditions. Am J Sports Med 12:233236, 1984

2. Broglio SP, Eckner JT, Surma T, Kutcher JS: Post-concussion cognitive declines and symptomatology are not related to concussion biomechanics in high school football players. J Neurotrauma 28:2061-2068, 2011

3. Broglio SP, Schnebel B, Sosnoff JJ, Shin S, Fend X, He X, et al: Biomechanical properties of concussions in high school football. Med Sci Sports Exerc 42:2064-2071, 2010

4. Broglio SP, Sosnoff JJ, Shin S, He X, Alcaraz C, Zimmerman $\mathrm{J}$ : Head impacts during high school football: a biomechanical assessment. J Athl Train 44:342-349, 2009

5. Brolinson PG, Manoogian S, McNeely D, Goforth M, Greenwald R, Duma S: Analysis of linear head accelerations from collegiate football impacts. Curr Sports Med Rep 5:23-28, 2006

6. Cantu RC, Mueller FO: Brain injury-related fatalities in American football, 1945-1999. Neurosurgery 52:846-853, 2003

7. Duma SM, Manoogian SJ, Bussone WR, Brolinson PG, Goforth MW, Donnenwerth JJ, et al: Analysis of real-time head accelerations in collegiate football players. Clin J Sport Med 15:3-8, 2005

8. Funk JR, Duma SM, Manoogian SJ, Rowson S: Biomechanical risk estimates for mild traumatic brain injury. Annu Proc Assoc Adv Automot Med 51:343-361, 2007

9. Funk JR, Rowson S, Daniel RW, Duma SM: Validation of concussion risk curves for collegiate football players derived from HITS data. Ann Biomed Eng 40:79-89, 2012

10. Gadd CW: Tolerable severity index in whole-head, nonmechanical impact, in: Proceedings of the 15th Stapp Car Crash Conference. New York: Society of Automotive Engineers, 1971, pp 809-816

11. Gadd CW: Use of weighted-impulse criterion for establishing injury hazard, in: Proceedings of the 10th Stapp Car Crash Conference. Warrendale, PA: Society of Automotive Engineers, 1966, pp 164-174

12. Greenwald RM, Gwin JT, Chu JJ, Crisco JJ: Head impact severity measures for evaluating mild traumatic brain injury risk exposure. Neurosurgery 62:789-798, 2008

13. Gurdjian ES: Cerebral contusions: re-evaluation of the mechanism of their development. J Trauma 16:35-51, 1976

14. Guskiewicz KM, Mihalik JP, Shankar V, Marshall SW, Crowell DH, Oliaro SM, et al: Measurement of head impacts in collegiate football players: relationship between head impact 


\section{J. A. Forbes et al.}

biomechanics and acute clinical outcome after concussion. Neurosurgery 61:1244-1253, 2007

15. Hodgson VR: National Operating Committee on Standards for Athletic Equipment football helmet certification program. Med Sci Sports 7:225-232, 1975

16. Lissner HR, Lebow M, Evans FG: Experimental studies on the relation between acceleration and intracranial pressure changes in man. Surg Gynecol Obstet 111:329-338, 1960

17. Pellman EJ, Viano DC: Concussion in professional football: summary of the research conducted by the National Football League's Committee on Mild Traumatic Brain Injury. Neurosurg Focus 21(4):E12, 2006

18. Pellman EJ, Viano DC, Tucker AM, Casson IR, Waeckerle JF: Concussion in professional football: reconstruction of game impacts and injuries. Neurosurgery 53:799-814, 2003

19. Rowson S, Duma SM: Development of the STAR evaluation system for football helmets: integrating player head impact exposure and risk of concussion. Ann Biomed Eng 39:21302140, 2011

20. Rowson S, Duma SM, Beckwith JG, Chu JJ, Greenwald RM, Crisco JJ, et al: Rotational head kinematics in football impacts: an injury risk function for concussion. Ann Biomed Eng 40:1-13, 2012

21. Schnebel B, Gwin JT, Anderson S, Gatlin R: In vivo study of head impacts in football: a comparison of National Collegiate
Athletic Association Division I versus high school impacts. Neurosurgery 60:490-496, 2007

22. Viano DC, Casson IR, Pellman EJ: Concussion in professional football: biomechanics of the struck player-part 14. Neurosurgery 61:313-328, 2007

23. Viano DC, Casson IR, Pellman EJ, Zhang L, King AI, Yang $\mathrm{KH}$ : Concussion in professional football: brain responses by finite element analysis: part 9. Neurosurgery 57:891-916, 2005

24. Viano DC, Pellman EJ, Withnall C, Shewchenko N: Concussion in professional football: performance of newer helmets in reconstructed game impacts-Part 13. Neurosurgery 59:591606, 2006

25. Zhang L, Yang KH, King AI: A proposed injury threshold for mild traumatic brain injury. J Biomech Eng 126:226-236, 2004

Manuscript submitted August 17, 2012.

Accepted September 27, 2012.

Please include this information when citing this paper: DOI: 10.3171/2012.9.FOCUS12288.

Address correspondence to: Jonathan Forbes, M.D., Department of Neurological Surgery, Vanderbilt University Medical Center, T-4224 Medical Center North, Nashville, Tennessee 37232. email: jonathan.forbes@vanderbilt.edu. 